\title{
Students' views and correlation regarding performance and attendance for a first year Engineering cohort
}

\author{
Diogo Montalvão \\ Department of Design and Engineering \\ Faculty of Science \& Technology, Bournemouth University \\ Poole House, Talbot Campus, Poole BH12 5BB, UK \\ dmontalvao@bournemouth.ac.uk
}

\author{
Mihai Dupac \\ Department of Design and Engineering \\ Faculty of Science \& Technology, Bournemouth University \\ Poole House, Talbot Campus, Poole BH12 5BB, UK \\ mdupac@bournemouth.ac.uk
}

\begin{abstract}
This paper presents a case study to assess the students' views and correlation between attendance to lectures, laboratories and seminars and their performance in terms of final results. The population is composed by a group of first year undergraduate students at the department of Design and Engineering, Bournemouth University, in an Engineering Design unit. Attendance was monitored for a number of 19 students over one academic year (2016-2017). Students' views regarding the impact of some factors - such as clear expectations, content easy to understand, student collaboration and interaction, peerpressure, and to be seen by the lecturer - on assessment performance have been surveyed. This data was obtained from a Likert scale survey ran over a population of 10 students in the 2017-2018 academic year. The data that correlates final marks with attendance (laboratory, lectures and seminars) was analysed and indicates a strong least-squares fit correlation between attendance and final marks, with a coefficient of correlation $\mathbf{R}^{2}=\mathbf{0 . 7 8}$ when plotting final marks vs overall attendance. Student view, which was also considered as an important aspect of this study, conveys the benefits of attending the lectures and quantify some of the factors mentioned above including a minimummaximum attendance rate for a good grade (first-class) or just a pass mark. Students perceive that the two main reasons for attending lectures are that, firstly, it makes it easier to understand the content and, secondly, they can get clear expectations on what they need to prepare and focus on.
\end{abstract}

Keywords- examination performance, class attendance, students' views, learning outcomes

\section{INTRODUCTION}

The correlation between regular attendance and academic performance in higher education has been the subject of various research studies including the ones reported by Aaron (2012), Gump (2005), Marburger (2001) and O’Dwyer (2011). Students' performance has been usually assessed directly using their final grades (Romer, 1993) or eventually by evaluating the accuracy of their answers in non-compulsory tests (Marburger, 2001)

Although a relatively small number of studies did not successfully observe a strong correlation between regular attendance and performance (Berenson et al., 1992), a clear majority (Gump, 2005; Clump et al., 2003) reported a significant or a positive correlation amidst them. The obtained results have potentially substantial implications regarding resource allocation and teaching time and delivery approach among different disciplines and courses requirements in higher education. Moreover, the pedagogical approach can be correlated to the students' views, in order to convey the maximum benefits for attending the lectures, thus making this kind of studies relevant to various disciplines, instructors and students (strong motivator to attend classes).

It has been reported by Romer (1993) that $25 \%$ attendance results in an "average earning of a 1.79 (C-)", while a $100 \%$ attendance materialize in an "average earning of a $3.44(\mathrm{~B}+)$ ". However, attendance quantify as one of many among other variables such as student's cumulative GPA (Grade Point Average), and background that relate and influence academic performance (Gump, 2005; Koppenhaver, 2006). Moreover, it has been shown (Friedman et al., 2001) that attendance was improved when it was included/related to the final results. Significant correlation between lecture attendance and examination performance of first-year biological sciences students - and particularly strong for non-UK students - has been reported in (Gatherer, 1998). Classroom participation and academic performance has been studied by (Babb and Ross, 2009) in conjunction to an improved attendance due to the lecture slides availability to students (either before or after lecture). The study reported an improved attendance but no significant variance in students' performance due to slides availability conditions

The impact of lecture attendance on academic performance was analysed by Andrietti (2014) for a course taught at a university in Italy using proxy variables regression. A positive and significant effect of attendance vs. a non-concluding effect due to unobservable student traits has been also discussed by Andrietti (2014). A significant weakly correlation between academic performance and lecture attendance was found by Maloney and Lally (1998) in a study performed at the University College Galway, Ireland. The relationship between learning performance and attendance - with classes not mandatory - has been examined by Lukkarinen et al. (2016) using cluster and regression analysis. It has been observed that 
attendance is positively and significantly related to performance for those who attend classes as well as the exam, while a good ability to proactively search for information have been reported for another group. A study relating the percentage of missing sessions to the final obtained grade in a Financial Management course (Senior, 2007) showed a strong statistically correlation between them and an average absenteeism of $24.4 \%$. Several of the above studies are either contrary or in favour of class attendance. However, no class attendance policy tend to be better endorsed against mandatory attendance which is considered more controversial (Senior, 2007).

In this paper, a case study to evaluate the correlation between students' attendance - laboratories, seminars and lectures - against their academic performance (e.g. final grades), has been considered. Attendance was monitored for a group of 19 undergraduate students over one academic year (2016-2017). The data that correlates final marks with attendance (laboratory, lectures and seminars) was analysed and indicates a significant correlation between overall attendance and performance with a correlation coefficient of $\mathrm{R}^{2}=0.78$ in a least-squares fit approach. To understand students' perceptions regarding the influence of attendance on academic performance, the views of 10 students related to some factors - such as expectations, easy to understand content, or peer-pressure, collaboration and interaction - have been collected using a Likert scale survey. The analysis substantiates the benefits of attending the lectures including their views on a minimum-maximum attendance rate for a good grade or just a pass mark. The main benefits perceived by students for attending lectures corroborate to a better understanding of the class expectations and content of the lectures, seminars or laboratories.

\section{METhodOLOGY}

\section{A. Participants}

Attendance - which was not mandatory - was monitored for a number of 19 undergraduate students at the department of Design and Engineering, during both first and second semesters of the academic year 2016-2017. An attendance sheet which was signed weekly by each student attending the Engineering Design unit was used to record attendance, procedure which was similar with recording of attendance considered in other studies such as Van Blerkom (1990) and Gump (2005).

No demographics criteria such as male vs. female, or subgroups representing foreign students, have been considered in the population used in the study. Attendance have been viewed either as global attendance or have been also clustered over 3 ranges. The range for good/excellent grades was considered from $65 \%$ to $100 \%$, medium/average grades are located between $45 \%$ and $65 \%$, and low grades are from $0 \%$ and $45 \%$.

To better understand the students' views regarding attendance and its impact on the assessment performance, some specific factors such as unit clear expectations, easy to understand content, or the significance of peer-pressure, and to be seen by the lecturer, have been surveyed. This data was collected using a Likert scale survey to allow some of the students attending the 2017-2018 Engineering Design unit to express their view.

\section{B. Materials}

Lectures were usually taught using PowerPoint slides, to both deliver the theoretical content and to present case studies for discussion with the class. These slides were uploaded on the Virtual Learning Environment (VLE) just before the lecture would start.

Seminars were usually more interactive, where students were presented with a problem they would have to solve. The lecturer would wander around the classroom discussing with the students their progress by providing formative feedback. The type of activities done in seminars included:

- Producing free-hand engineering drawings - these problems consisted of getting the students to train producing engineering drawings so that they had enough skills for the $1^{\text {st }}$ coursework in the unit, an individual assessment: "Sketches Portfolio";

- Discussing with the tutor their progress in the IMechE Design Challenge Competition - as part of the syllabus, students had to design and produce a device to compete in a competition organised by the IMechE (Institution of Mechanical Engineers), a UK professional, statutory and regulatory body. The device had to meet the requirements from a set of target specifications defined in the competition regulations. The outcome from this project was the $2^{\text {nd }}$ piece of assessment in the unit and it was a group project;

- Getting confidence in the selection and application of Geometrical Dimensioning \& Tolerancing (GD\&T) examples of practice included the calculation of limits and fits according to ISO 286:2010. Students had to do the reverse engineering of an existing product, producing all the annotated engineering drawings, including GD\&T, using Solidworks. This was the $3^{\text {rd }}$ (and final) piece of assessment and was individual.

There were also CAD Labs, where Solidworks was introduced to students. These practical sessions were accompanied with screenshots, given to students beforehand, of what was going to be done. The lecturer demonstrated the step-by-step instructions to what was being done and the sessions were video recorded using a software called Panopto. Whenever there was free time, students would be asked to solve a related problem on their own.

As it can be seen, all the work being produced during the seminars and CAD labs had a close relationship with the assessed coursework. However, students who would not be able to attend to sessions would have access to a comprehensive set of material from the VLE.

\section{RESUlTS}

Statistical analysis showing the correlation between final marks, portfolio marks and project marks vs. Lab or Lecture attendance, as well as the final marks vs. overall attendance is 
presented next. The data that correlates final marks with the overall attendance shown in Fig. 1 indicate a strong correlation with a coefficient of $\mathrm{R}^{2}=0.78$ (least-squares fit). The bar and whisker box plot in Fig. 1 indicate the variability and the degree of dispersion and asymmetry in the data for the 3 considered ranges of low grades ( $0 \%$ to $45 \%)$, medium/average grades $(45 \%$ to $65 \%)$, and good/excellent grades $(65 \%$ to $100 \%$ ) of the cluster.

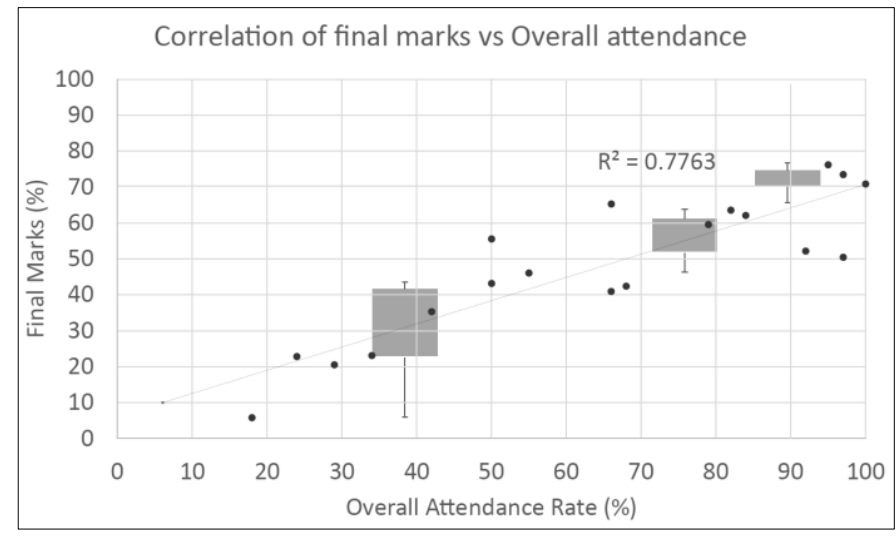

Fig. 1. Correlation between final marks and overall attendance.

Fig. 2 shows the correlation between the final marks vs. Lab or Lecture attendance. Since the content of the lectures and laboratory is very technical, the students with a good attendance are more likely to perform better than the others. This is validated by the obtained results showing in both cases a good correlation with either $\mathrm{R}^{2}=0.742$ or $\mathrm{R}^{2}=0.648$ respectively for the considered sample size of 19 students.
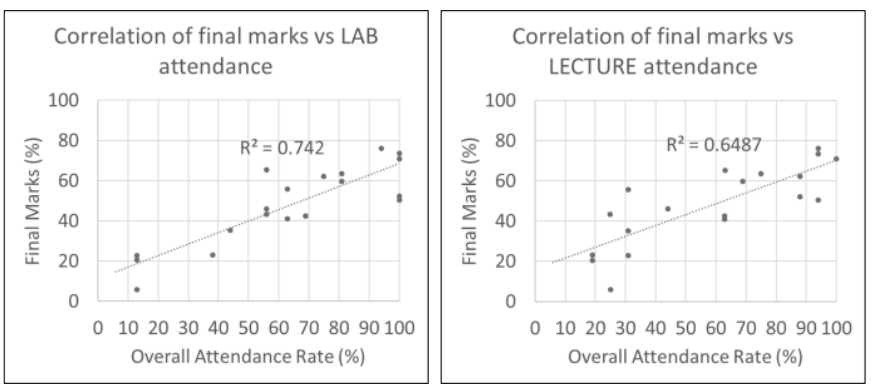

Fig. 2. Correlation between final marks and LAB / Lecture Attendance.

Figures 3 to 5 show the correlation between the marks obtained in each piece of assessment vs. Lab or Lecture attendance. It is interesting to note that the correlation between single pieces of assessment and attendance is not as high as when final results are correlated with attendance. In all cases, however, there seems to be a better correlation between marks and attendance to LABS than attendance to Lectures, as observed by other researchers before, for example Gbadamosi (2015). This may be because of a variety of reasons, one of which may be due to the fact that lectures usually are largegroup lecture sessions that contrast with small group interactive discussion sessions as are seminars, labs and tutorials.
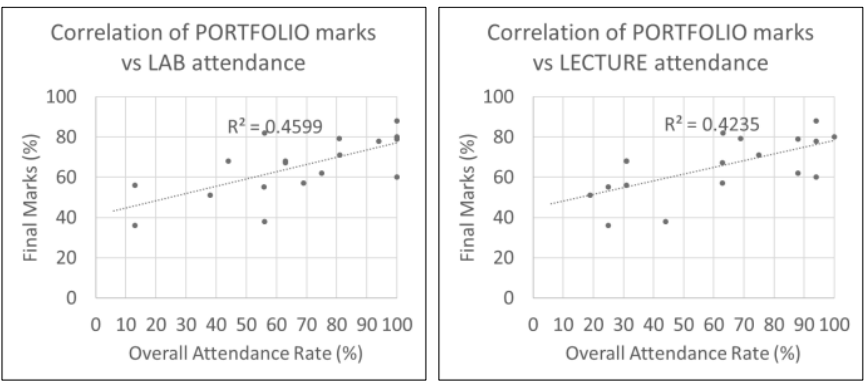

Fig. 3. Correlation between PORTOFOLIO and LAB / Lecture Attendance.
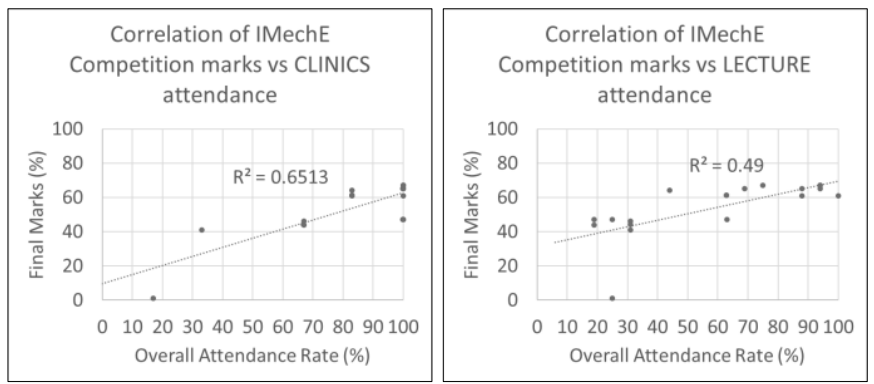

Fig. 4. Correlation between IMechE Competition and LAB (Team Clinics) / Lecture Attendance.
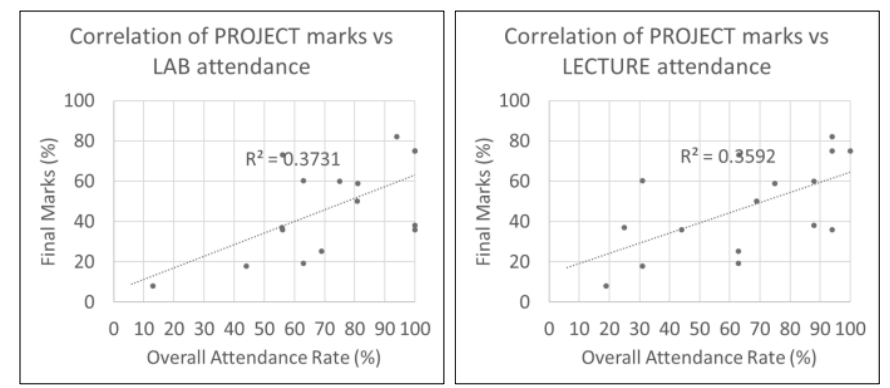

Fig. 5. Correlation between PROJECT and LAB / Lecture Attendance.

As mentioned by Lockwood et al. (2006), mandatory attendance of lectures is only one of the factors among others, e.g., student motivation, general knowledge and interest that would improve students' performance. Therefore, it was considered that students' view may represent an extra step for a better understanding of the benefits of attending the lectures. This data related to their view was obtained from a Likert scale survey using anonymous questionnaires on a scale of 1 to 10 , over a population of 10 students in the 2017-2018 academic year. The next sentence has been considered to collect data "My academic achievement was improved by attending the lectures, laboratories and seminars due to..."
A. Clear expectations of what I need to prepare and focus on.
B. The fact that I have been seen by the lecturer.
C. The fact that it was easier to understand the content by attending the lectures. 
D. Feeling I need to perform better when under peerpressure.

E. An improved learning due to the collaboration and interaction with other students.

F. The fact that academic achievement and attendance to lectures is correlated.

Students perceive that the two main reasons for attending lectures and improve academic achievement are firstly that it makes it easier to understand the content and, secondly, they can get clear expectations on what they need to prepare and focus, as shown in Figure 6. While the rest of the factors have been considered to be important, peer-pressure was not considered to be essential but still score high in their view.

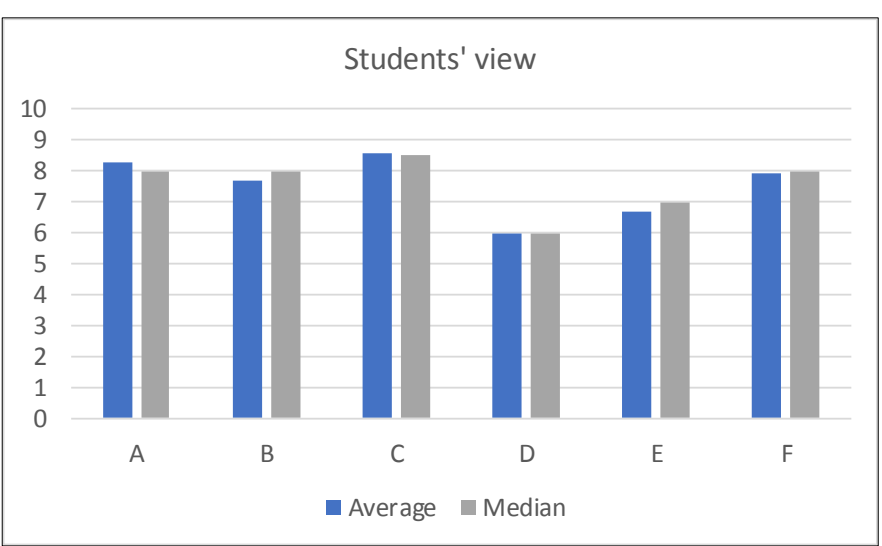

Fig. 6. Average and Median results for the questionnaire over a population of 10 students

The students also considered that a 55\% (mean) attendance of sessions will improve their chances for a pass mark (in the terminal examination) and that an attendance level of $90.5 \%$ in average will result in good chances to achieve a first class.

\section{CONCLUSIONS}

In this study the correlation between overall attendance respectively lectures, laboratories and seminars - over students' (a first-year undergraduate students cohort) academic performance is analysed. The results, which are consistent to others in similar studies, show that regular attendance result in better academic performance when compared with less regular attendance. The data that correlates final marks with attendance indicates a significant correlation with a coefficient $\mathrm{R}^{2}=0.78$. Since attendance in not the only factor which relate to a better academic performance, students' views such as class expectations, lectures' content easy to understand, etc., have been collected in a Likert scale approach. The survey spotlighted the benefits of attending the lectures and convey the central reasons for attending lectures, that is, it makes it easier to understand the content while getting clear expectations on what is needed to prepare and focus on.

[1] M.D. Aaron, "The relationship between attendance policies and student grades", Ph.D. Dissertation, The University of Alabama, Tuscalosa, Alabama, 2012

[2] V. Andrietti, "Does lecture attendance affect academic performance?", Panel data evidence for introductory macroeconomics, International Review of Economics Education, vol. 15, pp. 1-16, 2014

[3] K.A. Babb, C. Ross, "The timing of online lecture slide availability and its effect on attendance, participation, and exam performance", Computers \& Education, vol. 52, pp. 868-881, 2009.

[4] S. Berenson, G. Carter, and K. Norwood, "The at-risk student in college developmental algebra", School Science and Mathematics, vol. 92, pp. 55-58, 1992.

[5] M. Van Blerkom, "Class attendance in Undergraduate courses", Journal of Psychology, vol. 126, vol. 5, pp. 487-494, 1990.

[6] M. Clump, H. Bauer, and A. Whiteleather, "To attend or not to attend: Is that a good question? ", Journal of Instructional Psychology, vol. 30, pp. 220-224, 2003

[7] P. Friedman, F. Rodriguez, and J. McComb, "Why students do and do not attend classes: Myths and realities", College Teaching, vol. 49, pp. 124-33, 2001

[8] D. Gatherer and F.C.R. Manning, "Correlation of examination performance with lecture attendance: a comparative study of first-year biological sciences undergraduates", Biochemical Education vol. 26, pp 121-123, 1998.

[9] G. Gbadamosi, "Should we bother improving students' attendance at seminars?", Innovations in Education and Teaching International, vol 52, pp. 196-206, 2015.

[10] S. Gump, "The cost of cutting class: attendance as a predictor of student success", College Teaching, vol. 53, pp. 21-26, 2005.

[11] G. Koppenhaver, "Absent and accounted for: absenteeism and cooperative learning", Decision Sciences Journal of Innovative Education, vol. 4, pp. 29-49, 2006.

[12] A. Lukkarinen, P. Koivukangas and T. Seppälä, "Relationship between class attendance and student performance", HEAd'16, 21-23 June 2016 València, Spain, Procedia - Social and Behavioral Sciences, vol. 228, pp. 341-347, 2016.

[13] M. Maloney and B. Lally. The relationship between attendance at university lectures and examination performance, The Irish Journal of Education, Vol. 29, pp. 52-62, 1998

[14] D. Marburger, "Absenteeism and undergraduate exam performance", Journal of Economic Education, vol. 32, pp. 99-109, 2001.

[15] A. O'Dwyer, "Does a link exist between examination performance and lecture attendance for first year engineering students?", Proceedings of the $17^{\text {th }}$ International Conference on Engineering Education (ICEE), Belfast, Northern Ireland, 2011.

[16] D. Romer, "Do students go to class? Should they?", Journal of Economic Perspectives, vol. 7, pp. 167-74, 1993.

[17] B.A. Senior, "Correlation between Absences and Final Grades in a College Course", International Proceedings of the $44^{\text {th }}$ Annual Conference Associated Schools of Construction, Auburn, Alabama, paper CEUE275002008, 2008.

[18] P. Lockwood, C. Guppy and R. Smyth, "Should lectures be compulsory?", Proceedings of the UniServe Science Assessment Symposium, Sydney, Australia, pp. 178-181, 2006. 